\title{
Cause of death and associated conditions of stillbirths
}

\section{Naveen Prasanna ${ }^{1}$, Kavita Mahadevappa ${ }^{1}$, Ramalingappa C. Antaratani ${ }^{1}$, Laxmikant Lokare ${ }^{2}$}

\author{
${ }^{1}$ Department of Obstetrics and Gynecology, Karnataka Institute of Medical Sciences, Hubli - 580021, Karnataka, India \\ ${ }^{2}$ Department of Community Medicine, Karnataka Institute of Medical Sciences, Hubli - 580021, Karnataka, India
}

Received: 28 September 2015

Accepted: 29 October 2015

*Correspondence:

Dr. Kavita Mahadevappa,

E-mail: kavipgi10@gmail.com

Copyright: (c) the author(s), publisher and licensee Medip Academy. This is an open-access article distributed under the terms of the Creative Commons Attribution Non-Commercial License, which permits unrestricted non-commercial use, distribution, and reproduction in any medium, provided the original work is properly cited.

\begin{abstract}
Background: Fetal death is a psychological trauma for the expecting mother and their family. Most of the countries worldwide lack data on stillbirths. Simply counting stillbirths is the first step in analysis and prevention and hence stillbirths need to count. Purpose of the study is to know the incidence, cause of stillbirths and to plan cause specific interventions to reduce stillbirths.

Methods: This is a prospective cross-sectional study of patients with stillbirths from September 2014 to August 2015 in Karnataka Institute of Medical Sciences, Karnataka. All the cases who delivered stillbirths of weight more than $1 \mathrm{~kg}$, were grouped into the following CODAC (causes of death and associated conditions) simplified classification and were analysed.

Results: The total number of births during the study period was 9,863. Total number of stillbirths in our study period was 563. In the study period, the stillbirth rate was 57.9 per 1000 births, out of which $56.3 \%$ were in preterm pregnancy and $43.69 \%$ in term pregnancies. The three common causes of stillbirths were hypertensive disorders (34.63\%), intrapartum fetal loss $(27.17 \%)$ and abruptio placenta $(11.54 \%)$. In $7.9 \%$ of cases the cause of stillbirth was unknown. Nutritional anaemia, teenage pregnancy and intrauterine growth restriction were the most common associated conditions of stillbirths.

Conclusions: Anaemia and teenage pregnancy are the two important risk factors associated with stillbirths. Adolescent health education, folic acid and iron supplementation in schools has to be planned as a primary prevention of stillbirth. Early detection and treatment of hypertensive disorders and good intrapartum care, will help us in reducing the stillbirth rate to a large extent, as these are the two important causes of stillbirth.
\end{abstract}

Keywords: CODAC simplified, Stillbirths rate, Intrauterine fetal death, Cause of stillbirth

\section{INTRODUCTION}

Healthy mother and healthy baby is not only the aim of every obstetrician, but also the expecting mother and her family. Fetal death is a psychological trauma for the expecting mother and their family. Fetal death or stillbirth are estimated to account for more than half of the world's perinatal deaths, but only a fraction are registered in any health organization. At least 2.64 million stillbirths (uncertainty range 2.14 million to 3.82 million) were estimated worldwide in 2009 ( $\geq 1000 \mathrm{~g}$ birth weight or $\geq 28$ weeks of gestation). ${ }^{1}$ Stillbirths of upto $98 \%$ occur in low-income and middle-income countries, and numbers vary from 2.0 per 1000 total births in Finland to more than 40 per 1000 total births in Nigeria and Pakistan. Worldwide, $67 \%$ of stillbirths occur in rural families, $55 \%$ in rural sub-Saharan Africa and south Asia, where skilled birth attendance and caesarean sections are much lower than that for urban births. It is estimated that some 1.8 million stillbirths occur in ten countries - India, Pakistan, Nigeria, China, Bangladesh, Democratic Republic of the Congo, Ethiopia, Indonesia, Afghanistan and United Republic of 
Tanzania. Half of all stillbirths occur in India, Pakistan, Nigeria, China and Bangladesh alone. ${ }^{2}$ There has been a difference in the cut off for gestational age and weight of the fetus, for labeling of stillbirth from country to country. This has been changing from time to time worldwide. This adds to the confusion and the difference in the statistics of stillbirths. The World Health Organisation and International Centre for Diseases have come out wth a common definition for stillbirth. According to them, stillbirth is defined as, death of fetus that has reached 500 gms or if birth weight is unavailable, gestational age of 22 weeks or crown to heel length of 25 cms. WHO also recommends using a higher limit (1000 gms or if birth weight is unavailable, gestational age of 28 weeks or crown to heel length of $35 \mathrm{~cm}$ ) of third trimester stillbirths for international comparison. ${ }^{3}$ Most of the countries worldwide lack data and proper reporting of still births. Simply counting stillbirths is the first step in analysis and prevention and hence stillbirths need to count. Purpose of the study is to know the cause of still birth and plan cause specific interventions, to reduce stillbirths rates effectively.

\section{METHODS}

This is a prospective cross-sectional study of patients with stillbirths from September 2014 to August 2015 in Karnataka Institute of Medical Sciences, Karnataka. All the cases who were admitted with the diagnosis of Intrauterine fetal death or who had intrauterine fetal death in our hospital, and delivered stillbirth of weight more than $1 \mathrm{~kg}$ were included in our study. The detailed antenatal history was taken and the patients were investigated. Including Hemoglobin, Thyroid profile, Blood sugar profile, renal function tests were done. The antenatal cards and intrapartum notes were scrutinized. The stillbirths were grouped into the following CODAC (Causes of Death and Associated Conditions) simplified classification. ${ }^{4}$ The cause of death were grouped as Infection, Intrapartum, Congenital anomaly, Fetal, Cord, Placenta, Maternal, and unknown causes. The following associated conditions were also looked for- fetal growth restriction, maternal nutritional anemia, maternal medical diseases, low and high maternal age, bad obstetric history and prolonged pregnancies. Each case was given one cause of death based on the primary event which led to fetal death. Each case was looked for any two associated conditions which may or may not directly cause fetal death, but definitely aggravates the primary event, which led to fetal death. Postpartum follow up was done till discharge and after 6weeks. Chi square test was used for statistical ananlysis.

\section{RESULTS}

The total number of births during the study period was 9,863. Total number of stillbirths in our study period was 563. The stillbirth rate in our institute, in the study period is 57.9 per 1000 births. The demography of the patients with stillbirths are shown in table 1. Majority of women were primigravida (48.2\%), most of the stillbirths $(56.3 \%)$ occurred in preterm pregnancy and there were 318 male and 245 female stillbirths. Maximum numbers of stillbirths $(46.67 \%)$ were seen with fetal weight between $1-2 \mathrm{kgs}$, as depicted. Most of stillbirths were seen in the antepartum period $(72.82 \%)$ when compared to intapartum period (27.17\%). Distribution of the cause of stillbirth is shown in Table 2. The most common causes of stillbirths in our study was Hypertensive diorders $(34.63 \%)$, Intrapartum fetal death $(27.17 \%)$ and Abruptio placenta(11.54\%). Congenital malformations contributed to $4.16 \%$ stillbirths. There were two fetal deaths with $\mathrm{Rh}$ isoimmunisation. In $7.9 \%$ of cases the cause of stillbirth was unknown. Out of 195 cases of stillbirths due to hypertensive disorders, $51.8 \%$ were preterm and $48.2 \%$ were term, and the difference is not statistically significant. Out of 65 cases of stillbirths due to abruption placenta, $36.92 \%$ were term and $63.08 \%$ were preterm, and the difference is not statistically significant. Hence hypertensive disorder and abruption placenta are causing stillbirths in term pregnancy as much as in preterm pregnancy, whereas intrapartum loss were more in term $(83.66 \%)$ pregnancy when compared to preterm pregnancy $(16.33 \%)$, which was statistically significant as shown in table 3 . The associated conditions of stillbirths are depicted in table 4. Nutritional anaemia was seen as associated condition in $310(55.06 \%)$ patients out of 563 cases. The next common associated condition seen was low maternal age $196(34.81 \%)$ patients out of 563 cases. Intrauterine growth restriction was seen in 140 $(24.86 \%)$ patients out of 563 cases.

Table 1: Demography of patients.

\begin{tabular}{|lll|}
\hline \multicolumn{1}{|c|}{ Age in Year } & Cases & Percentage (\%) \\
\hline$<20$ & 196 & 34.9 \\
\hline $21-30$ & 313 & 55.6 \\
\hline$>30$ & 54 & 9.59 \\
\hline Parity & & \\
\hline Primigravida & 280 & 49.73 \\
\hline Gravida 2 & 114 & 20.02 \\
\hline Gravida 3 and above & 169 & 30.01 \\
\hline Sex of Fetus & & \\
\hline Female & 245 & 43.51 \\
\hline Male & 318 & 56.48 \\
\hline Fetal Weight & & \\
\hline 1-1.9kg & 264 & 46.9 \\
\hline 2-2.9kg & 218 & 38.72 \\
\hline$\geq 3 \mathrm{~kg}$ & 81 & 14.38 \\
\hline Gestation & \\
\hline Term $>/=37 w k s)$ & 246 & 43.69 \\
\hline Preterm $(<37 w k s)$ & 317 & 56.30 \\
\hline
\end{tabular}

\section{DISCUSSION}

From our study the stillbirth rate is 57.9 per 1000 deliveries. Ours is a tertiary care centre catering a large part of north Karnataka, hence this institute receives all 
Table 2: Causes of stillbirths.

\begin{tabular}{|c|c|c|c|c|}
\hline \multicolumn{3}{|c|}{ Causes of fetal death } & Cas & Percen \\
\hline 1 & Infection & & 15 & 2.66 \\
\hline \multirow{4}{*}{2} & \multirow{4}{*}{ Intrapartum } & Malpresentation & \multirow{4}{*}{$\begin{array}{l}45 \\
33 \\
10 \\
65\end{array}$} & 7.99 \\
\hline & & $\begin{array}{l}\text { Prolonged/Obstructed } \\
\text { labour }\end{array}$ & & 5.86 \\
\hline & & Rupture uterus & & 1.77 \\
\hline & & Respiratory Failure & & 11.54 \\
\hline 3 & \multicolumn{2}{|c|}{ Congenital Anomalies } & 26 & 4.61 \\
\hline \multirow{2}{*}{4} & \multirow[t]{2}{*}{ Fetal } & Isoimmunisation & 2 & \multirow{2}{*}{0.35} \\
\hline & & immune Hydrops & 0 & \\
\hline \multirow{2}{*}{5} & \multirow{2}{*}{ Cord } & Knots/Loops & 14 & 2.48 \\
\hline & & Prolapse/Accidents & 7 & 1.24 \\
\hline \multirow{2}{*}{6} & \multirow{2}{*}{ Placenta } & Abruptio & \multirow{2}{*}{$\begin{array}{l}65 \\
7 \\
\end{array}$} & 11.54 \\
\hline & & Praevia & & 1.24 \\
\hline \multirow[t]{2}{*}{7} & \multirow{2}{*}{ Maternal } & $\begin{array}{l}\text { Hypertensive } \\
\text { disorders }\end{array}$ & \multirow{2}{*}{$\begin{array}{l}195 \\
19\end{array}$} & 34.63 \\
\hline & & Diabetes & & 3.37 \\
\hline \multicolumn{3}{|c|}{8 Unknown } & 60 & 7.9 \\
\hline \multicolumn{3}{|c|}{ Total } & 563 & 100 \\
\hline
\end{tabular}

Table 3: Most common causes of stillbirths in relation to preterm and term pregnancies.

\begin{tabular}{|lccl|}
\hline \multicolumn{1}{|c}{$\begin{array}{c}\text { Causes of } \\
\text { stillbirths }\end{array}$} & \multicolumn{1}{c}{ Term } & \multicolumn{1}{c}{ Preterm } & P value \\
$\begin{array}{l}\text { Hypertensive } \\
\text { disorders }\end{array}$ & $94(48.20 \%)$ & $101(51.80 \%)$ & 0.11625 \\
\hline $\begin{array}{l}\text { Intrapartum } \\
\text { loss }\end{array}$ & $128(83.66 \%)$ & $25(16.33 \%)$ & 0.0 \\
\hline $\begin{array}{l}\text { Abruptio } \\
\text { placenta }\end{array}$ & $24(36.92 \%)$ & $41(63.08 \%)$ & 0.241891 \\
\hline
\end{tabular}

Chi square test applied, $\mathrm{p}$ value $<0.05$ is significant

the complicated cases of pregnancies from neighbouring 4 districts. This could be the cause of higher rate of stillbirth. Similar results were seen in a study done in a tertiary care center, Uttarakhand which showed stillbirth rate of 49/1000 births. ${ }^{5}$ The stillbirth rate varies sharply country by country, based on definition and limits of gestational age and weight of still births. Prior to 2006, no organization had published global, regional or country-specific stillbirth rates. A global series of stillbirth estimates for the year 2000 was published in 2006 by WHO. It has been indicated that there are substantial differences of data at the country level. ${ }^{6}$ Rates also varied widely within countries. According to Cousens $\mathrm{s}$ et al, in India stillbirths rates ranged from 20 to 66 per 1000 births in different states in 2009. ${ }^{1}$ The still birth rate as reported for year 2010 was only 7 per 1000 births. $^{7}$ Still birth rate of India for 2012 is estimated at five per 1,000 births with the highest in Karnataka(14) and the lowest in $\operatorname{Bihar}(1) .{ }^{8}$ The estimated values of stillbirth rate are likely to be underestimates, as data on stillbirths is difficult to capture, as most of
Table 4: Associated conditions of stillbirths.

\begin{tabular}{|c|c|c|c|c|}
\hline \multicolumn{3}{|c|}{ Associated conditions } & Cases & $\begin{array}{c}\text { Percentage } \\
(\%)\end{array}$ \\
\hline 1 & \multicolumn{2}{|c|}{ Nutritional Anaemia } & 310 & 55.06 \\
\hline \multirow{9}{*}{2} & \multirow{9}{*}{$\begin{array}{l}\text { Maternal } \\
\text { disease }\end{array}$} & Heart disease & \multirow{9}{*}{$\begin{array}{l}2 \\
3 \\
6 \\
1 \\
1 \\
1 \\
1\end{array}$} & \multirow{9}{*}{$\begin{array}{l}0.35 \\
0.53 \\
1.06 \\
0.17 \\
0.17 \\
0.17 \\
0.17\end{array}$} \\
\hline & & Hypothyroidism & & \\
\hline & & Respiratory & & \\
\hline & & diseases & & \\
\hline & & Burns & & \\
\hline & & Hyperthyroidism & & \\
\hline & & Rheumatoid & & \\
\hline & & arthritis & & \\
\hline & & Renal disease & & \\
\hline 3 & \multicolumn{2}{|c|}{ Low Maternal age } & 196 & 34.81 \\
\hline 4 & \multicolumn{2}{|c|}{ High Maternal age } & 10 & 1.77 \\
\hline 5 & \multicolumn{2}{|l|}{ IUGR } & 140 & 24.86 \\
\hline 6 & \multicolumn{2}{|l|}{$\mathrm{BOH}$} & 7 & 1.24 \\
\hline 7 & \multicolumn{2}{|c|}{ Post term pregnancy } & 23 & 4.08 \\
\hline 8 & \multicolumn{2}{|c|}{ Multiple pregnancy } & 18 & 3.19 \\
\hline
\end{tabular}

them go unnoticed because of home delivery. This has been shown in the report, "State of Newborns 2014" given by Ministry of Health, India. ${ }^{9}$

There are more than 30 classifications described in literature over 50 years. Froen et al, in 2009 compared few important classifications with ICD system and suggested CODAC classification is one of the best options to supplement ICD. ${ }^{10}$ ICD system has international consensus on classification system for stillbirth. The current ICD,${ }^{10}$ does not fully recognize the stillborn (with cord, placenta and membranes), as an individual entity with its own diseases conditions and events to be registered separately from the mother. There are limited codes for conditions specific to the perinatal period in the $\mathrm{O}$ code (pregnancy, childbirthand puerperium from maternal perspective) and $\mathrm{P}$ codes (certain conditions originating in the perinatal period originating from the fetal perspective) where adequate coding for stillbirth should be found. Placental codes in particular are incomplete and can be used for only few of the placental pathologies affecting pregnancy outcome. ICD aims to classify the underlying cause of death and when not available, the condition most likely to have caused death. It is used so extensively in low income countries. CODAC classification on the other hand is an expandable classification. This allows simple data collection from verbal autopsy useful in low income countries. These categories are expandable to individual diagnosis in high resource, high expert settings with higher investigations and autopsy, which allows specific pathological, anatomical diagnosis of IUD (Intrauterine death). CODAC simplified is used in our study.

In our study antepartum stillbirths were $72.87 \%$ and the rest were intrapartum stillbirths. Hypertensive disorders (34.63\%), intrapartum fetal loss $(27.13 \%)$ and abruption $(11.54 \%)$ were the three main causes of stillbirth. Similar 
results were seen in uttarakhand, where the main cause of stillbirths was hypertensive disorders (28.75\%). A retrospective review of stillbirths using CODAC classification done by Wilkin's et al, where one hundred and fifty-three stillbirths were identified, producing a stillbirth rate of 29 per 1000 births. Of stillbirths with known timing, $70(66.7 \%)$ occurred antepartum and $35(33.3 \%)$ intrapartum. Cause of death could not be ascertained in $62.7 \%$ of cases due to poor or missing records. Where identified, the three most commonly classified causes of death were intrapartum fetal asphyxia, maternal infection and maternal hypertensive disorder. ${ }^{11}$ In a population based study by Bukowski R et al, out of 663 women with stillbirth, a possible or probable cause of death in 390 was identified. The most common causes were obstetric conditions (29.3\%), placental abnormalities (23.6\%), fetal genetic/structural abnormalities (13.7\%), infection (12.9\%), umbilical cord abnormalities (10.4\%), hypertensive disorders $(9.2 \%)$, and other maternal medical conditions $(7.8 \%){ }^{12}$ In our study congenital malformations were $4.6 \%$, infection were $2.6 \%$, cord accidents were $3.7 \%$ and unexplained stillbirths were $7.99 \%$. In the uttarakhand study $19.05 \%$ stillbirths were attributed to unexplained causes, $10.48 \%$ due to congenital malformations, $1.9 \%$ due to cord accidents, $7.6 \%$ due to infections. ${ }^{5}$

In high income countries, fetal death during labour is rare, although congenital or karyotypic anomalies are often identified as causes of stillbirth. ${ }^{13}$ However, in approximately half of all stillbirths, a specific cause cannot be identified, even in high income countries where placental pathological examinations and autopsies are available. $^{14}$ In low and middle income countries, infections such as syphilis, gram-negative infections, gestational hypertensive disorders, especially poor management of pre-eclampsia and eclampsia, malaria in first pregnancy with malaria-endemic areas, and obstructed or prolonged labour with associated asphyxia, infection, and birth injury with low availability of caesarean section are the most common causes. ${ }^{15}$ In our study preterm stillbirth was $56.3 \%$ and term stillbirth is $43.69 \%$. Hypertensive disorder and abruption placenta are causing stillbirths in term pregnancy as much as in preterm pregnancy, whereas intrapartum loss were more in term pregnancy when compared to preterm pregnancy. A Bulgarian study showed preterm stillbirth in 53\% and term stillbirth in $39 \%$, and also shows that preeclampsia was an important cause of stillbirths in preterm pregnancy and umbilical cord accidents, unexplained stillbirths in term pregnancy ${ }^{16}$ The common associated conditions of stillbirth in our study was nutritional anaemia, seen in $310(55.06 \%)$ patients out of 563 cases. The next common associated cause seen was low maternal age 196 (34.81\%) patients out of 563 cases. Intrauterine growth restriction was seen in $140(24.86 \%)$ patients out of 563 cases. In a case controlled study done in Norway, based on CODAC classification, two third of cases $(68 \%)$ stillbirths were associated with placental pathology ${ }^{17}$. In our study only ten patients were above $30 y$ rs of age. Postterm pregnancy, multiple pregnancy and $\mathrm{BOH}$ were seen as associated causes in 23,18 and 7 stillbirths respectively. Major risk factors for stillbirths in high-income countries are maternal overweight and obesity, maternal age over 35 years, primiparity, and smoking. ${ }^{18}$ Whereas in developing countries, malnutrition underweight, teenage pregnancy and multiparity are the risk factors. Bhutta et al reviewed 35 potential interventions to prevent stillbirths, of which they strongly recommended 10 for implementation: periconceptional folic acid fortification, insecticide-treated bed nets or intermittent preventive treatment for malaria prevention, syphilis detection and treatment, detection and management of hypertensive disease of pregnancy, detection and management of diabetes in pregnancy, detection and management of fetal growth restriction, routine induction to prevent post-term pregnancies, skilled care at birth, basic emergency obstetric care and comprehensive emergency obstetric care. ${ }^{19}$ After knowing the causes of death and associated causes of stillbirths in our study, it is evident that the above mentioned interventions are also required to be implemented judiciously to reduce the stillbirth.

Anaemia and teenage pregnancy are the two important risk factors associated with stillbirths. Adolescent health education, folic acid and iron supplementation in schools has to be planned as a primary prevention of stillbirth. Early detection and treatment of hypertensive disorders and good intrapartum care, will help us in reducing the stillbirth rate to a large extent, as these are the two important causes of stillbirth.

\section{Funding: No funding sources \\ Conflict of interest: None declared \\ Ethical approval: The study was approved by the Institutional Ethics Committee}

\section{REFERENCES}

1. Cousens S, Blencowe H, Stanton C, Chou D, Ahmed $\mathrm{S}$, Steinhardt L, et al. National, regional, and worldwide estimates of stillbirth rates in 2009 with trends since 1995:a systematic analysis. Lancet. 2011;377(9774):1319-30.

2. Lawn JE, Blencowe H, Pattinson R, Cousens S, Kumar R, Ibiebele I. Stillbirths: Where? When? Why? How tomake the data count? Lancet. 2011;377(9775):1448-63.

3. World Health Organization: ICD-10: International Statistical Classification of Diseases and Related Health Problems - Instruction Manual. 2nd edition. Geneva, Switzerland: World Health Organization; 2004. September 2015.

4. Frøen JF, Pinar H, Flenady V, Bahrin S, Charles A, Chauke L. Causes of death and associated conditions (CODAC) - a utilitarian approach to the classification of perinatal deaths. BMC Pregnancy Childbirth. 2009;9:22. 
5. Choudhary A, Gupta V. Epidemiology of Intrauterine Fetal Deaths: A Study In Tertiary Referral Centre In Uttarakhand IOSR Journal of Dental and Medical Sciences (IOSR-JDMS) e-ISSN: 2279-0853, p-ISSN: 2279-0861. Volume 13, Issue 3 Ver. II. (Mar. 2014), PP 035b.

6. World Health Organization (WHO). Perinatal and neonatal mortality for the year 2000: Country, regional and global estimates. Geneva, 2006. September 2015.

7. Census of India. Estimates of mortality indicators 2010. September 2015.

8. Registrar General of India. Sample Registration System (SRS) statistical report 2012. September 2015.

9. PHFI, AIIMS, and SC- State of India's Newborns (SOIN) 2014- a report. (Eds) Zodpey S and Paul VK. Public Health Foundation of India, All India Institute of Medical Sciences and Save the Children. New Delhi, India.

10. Frøen JF, Gordijn SJ, Abdel-Aleem H, Bergsjø P, Betran A, Duke CW. Making stillbirths count, making numbers talk - issues in data collection for stillbirths. BMC PregnancyChildbirth. 2009.

11. Wilkins A, Earnest J, Mccarthy EA, Shub A. A retrospective review of stillbirths at the national hospital in Timor-Leste. Aust N Z J Obstet Gynaecol. 2015.

12. Bukowski R, Carpenter M, Conway D, Coustan D, Dudley DJ, Goldenberg RL. Causes of death among stillbirths. JAMA. 2011.

13. Yakoob MY, Lawn JE, Darmstadt GL, Bhutta ZA. Stillbirths: epidemiology, evidence, and priorities for action. Seminars in Perinatology 2010;34(6):387-94.
14. Silver RM, Varner MW, Reddy U, Goldenberg R, Pinar H, Conway D. Work-up of stillbirth: a review of the evidence. American Journal of Obstetrics and Gynecology. 2007;196(5):433-44.

15. McClure EM, Nalubamba-Phiri M, Goldenberg RL. Stillbirth in developing countries. International Journal of Gynecology \& Obstetrics. 2006;94(2):8290.

16. Dimitrov G, Frandeva B, Garnizov T, Zlatkov V, Dimitrov A. Causes of stillbirths according to the period of pregnancy. Akush Ginekol (Sofiia). 2014;53(3):3-7.

17. Helgadóttir LB, Turowski G, Skjeldestad FE, Jacobsen AF, Sandset PM, Roald B et al. Classification of stillbirths and risk factors by cause of death - a case-control study. Acta Obstet Gynecol Scand. 2013;92(3):325-33.

18. Flenady V, Koopmans L, Middleton P, Frøen JF, Smith GC, Gibbons K. Major risk factors for stillbirth in high-income countries: a systematic review and metaanalysis. Lancet. 2011;377(9774):1331-40.

19. Bhutta ZA, Yakoob MY, Lawn JE, Rizvi A, Friberg IK, Weissman E. Stillbirths: what difference can we make and at what cost? Lancet. 2011;377(9776):1523-38.

Cite this article as: Prasanna N, Mahadevappa K, Antaratani RC, Lokare L. Cause of death and associated conditions of stillbirths. Int J Reprod Contracept Obstet Gynecol 2015;4:1970-4. 